\title{
Typology and language change: The case of truncation
}

\section{Birgit Alber}

Free University of Bozen-Bolzano

birgit.alber@unibz.it

\section{Joachim Kokkelmans}

Free University of Bozen-Bolzano

jkokkelmans@unibz.it

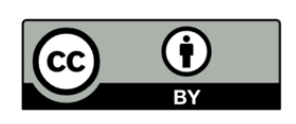

Received: 15-03-2021

Accepted: 30-09-2021

Published: 22-02-2022

How to cite: Alber, Birgit \& Kokkelmans, Joachim. 2022. Typology and language change: The case of truncation. RLLT17, eds. Ora Matushansky, Laurent Roussarie, Michela Russo, Elena Soare \& Sophie Wauquier. Special issue of Isogloss Open Journal of Romance Linguistics $8(2) / 13,1-17$.

DOI: https://doi.org/10.5565/rev/isogloss.124

\begin{abstract}
Diachronic change of prosodic structures, as it is encountered for instance in the history of stress systems, has been described as a slow process involving a series of minimal changes in a language's grammar (Lahiri, 2015). We show that minimal grammatical change of prosodic structures is observed as well in the domain of name truncation (e.g. Italian hypocoristic formation: Francesca $>$ France), where diachronic change is fast and therefore analyzable in real time. Following a study by Boschiroli (2017) on the perceived age of Italian truncation patterns, we establish a relative chronology of French and German truncation patterns and propose an analysis where minimality in language change is defined in terms of the ranking conditions (typological properties) determining the typological system of truncation.
\end{abstract}


Keywords: name truncation, typology, language change, Property Theory

\section{Grammatical change and minimality*}

Language change targeting prosodic structure bears the clear signs of change in the grammar of a language's linguistic system. Stress patterns, for instance, might change from aligning main stress to the left edge of the word to systems with right-aligning main stress, as has been observed for the evolution from Preclassical to Classical Latin as well as for the diachrony of the metrical system of most Germanic languages (Alber, 2020; Dresher, 2013; Jacobs, 2003; Lahiri, 2015; Speyer, 2009; Zonneveld, 1999). The opposite change, from a system where main stress is aligned rightmost to one where it is aligned leftmost, seems to have taken place from Old to Modern Bengali (Lahiri, 2015). However stress may be analysed, this is a change in the binary setting (leftmost vs. rightmost) that natural languages allow for the placement of word stress. Similarly, a change of grammatical settings must be involved in the variation of foot-type, as observed in prosodic systems of related languages of the Panoan family (González, 2017). Changes in prosodic structure are thus not dissimilar to grammar change observed in syntax (Kroch, 2001).

A further trait of change in the prosodic structure of a language, which recalls other phenomena of language change, is that it seems to proceed one minimal step at a time. Thus, Lahiri (2015) observes that English word stress undergoes four stages, from Old to Modern English, each characterized by the switch of a single parameter determining extrametricality, directionality of foot-parsing or placement of main stress.

Here, we study grammatical change in a specific domain of prosodic morphology: the domain of the word-formation process of name truncation. Grammatical constraints conditioning name truncation typically refer to the size of the truncatum, which often is either mono- or disyllabic (compare Italian Francésca ${ }^{1}>$ Fránce with Francésca $>$ Fra) and to its anchor point, i.e. the type of position copied from the base name. Anchor points include the left or right word edge (compare Francésca > Fránce with German Ánton > Tón-i) and the stressed syllable of the base name (e.g. Francésca $>$ Césca).

When considering diachronic change in the patterns of name truncation, it becomes immediately clear that unlike the diachronic change of stress, language change in name truncation is very fast. While stress systems seem to be particularly resistant to language change (cf. ibid., who refers to this trait as pertinacity), patterns of name truncation are subject to continuous change. The reason might well be in the pragmatic function of the latter, which often is connected to expressing 'closeness' (Alber \& Arndt-Lappe, 2012). As is the way with phenomena expressing functions like these, patterns sounding modern and cool today will be considered

* We thank all anonymous participants in the data elicitation task as well as Laura Boschiroli, for sharing their data with us. Special thanks go to Martina Nagler, for providing expertise on the newest truncation patterns used in South Tyrol as well as to Katia De Gennaro, for acting as Versuchskaninchen for various incarnations of the online questionnaire. For comments we thank the audience at Birgit Alber's keynote talk at the $34^{\text {th }}$ Going Romance conference. Birgit Alber takes responsibility for sections 1-2, Joachim Kokkelmans for sections 3-4, both authors for section 5. The paper has to be considered the result of a joint effort of both authors.

1 Whenever relevant, we indicate the location of main stress with an acute accent on the stressed vowel. 
obsolete and sometimes even embarrassing by tomorrow's generation. The fast turnover of patterns makes name truncations an ideal testing ground for the study of grammatical change and its supposed feature of minimal progression from one pattern to the next.

We base our investigation of language change in truncation on the analysis in Alber \& Arndt-Lappe (submitted), where the typological system of truncation is analysed in the framework of Optimality Theory. Alber \& Arndt-Lappe (ibid.) undertake a property analysis (Alber \& Prince, 2015, 2017, in prep.) of the typology, extracting its defining ranking conditions or typological properties. Property analysis allows us to give a precise definition of the concept of 'minimal grammatical change': the grammars of two languages differ minimally if they differ by not more than one property value. We hypothesize that single steps in the diachrony of prosodic change are characterized by grammatical minimality of this type.

In order to apply the concept of minimal change in grammar to a set of data from natural languages, we elicited the perceived age of truncation patterns from speakers of French and German, following a similar study undertaken by Boschiroli (2017) for Italian. The elicited data first of all shows that a relative chronology between (groups of) truncation patterns can be established in the three languages. Secondly, when patterns are assigned property values, we see that it is indeed possible to establish a diachronic path involving what can be interpreted as a minimal change in property values.

\section{A typological analysis of truncation}

Alber \& Arndt-Lappe (submitted) base their typological analysis of truncation on a database of approximately 150 patterns spread over more than 40 languages, collected from the literature and own fieldwork. They create a typological model, BTT (Basic Truncation Typology, see also Alber 2017), with the help of OTWorkplace (M. Prince \& Tesar, 2007-2022), a software suite for the Excel environment providing essential tools for the generation and analysis of linguistic typologies in Optimality Theory.

Alber \& Arndt-Lappe (submitted) implement BTT on the basis of a set of candidates consisting in pairs of mappings of input base names to output truncated forms (BTT.Gen). Stress may fall on any syllable of the input and possible outputs consist in all contiguous nonempty substrings of the corresponding input form. They calculate the typology for input strings from two to five syllables.

To guarantee focus on the size and anchoring properties of truncation and to abstract away from segmental phenomena which might blur the picture, Alber \& Arndt-Lappe (ibid.) use an abstract representation for input forms as strings of syllables represented by ordered strings of letters where stress is indicated by capitals. A base name such as Italian Valentina would therefore be represented as [abCd] (four syllables, penultimate main stress). The set of possible output forms of this string includes all contiguous substrings, i.e. [a, b, C, d, ab, bC, $\mathrm{Cd}, \mathrm{abC}, \mathrm{bCd}, \mathrm{abCd}]$. Some of these output forms correspond to attested truncation patterns of Italian (e.g. [ab], which represents left-anchored, disyllabic Vále) ${ }^{2}$ others do not occur in Italian, nor in any other language, as e.g. the monosyllabic output form [b] (=Valentina $>$ Le), which is anchored neither to the left, nor to the right edge, nor to the stressed syllable of the base. Among all possible input-output mappings, evaluation of the candidates by the proposed set of constraints should yield all and only those forms which are attested in natural languages.

$2 \quad$ Vále is represented as [ab] since it preserves the first and second input syllables. They are not stressed in the input, hence the lower case of [ab]. It is of no consequence that Vále bears penultimate stress, which we assume to be assigned by default to the truncatum, in accordance with the language's stress rules. 
Alber \& Arndt-Lappe (submitted) propose a set of five constraints, two of which refer to the size of truncated forms (mono- or disyllabic), three to the anchor-points targeted by truncation (the left and right edge of the word and the stressed syllable):

(1) BTT.Con: constraints active in determining the typology of truncation; (ibid.)

a. Constraints referring to the size of the truncatum ('TMPL constraints')

- m.1s: Return $n-1$ violation mark(s) for an output string of $n$ syllables (the output is minimally and maximally monosyllabic)

- m.2s: Return $n-2$ violation marks for an output string $>2$, consisting of $n$ syllables; return one violation mark for an output string consisting of a single syllable (the output is minimally and maximally disyllabic)

b. Constraints referring to anchoring ('PROM constraints')

- f.AnchL (Anchor-Left): Let y' be the first syllable of the output and y its correspondent in the base; return one violation mark for every syllable $\mathrm{x}$ in the base preceding $\mathrm{y}$.

- f.AnchR (Anchor-Right): Let y' be the last syllable of the output and y its correspondent in the base; return one violation mark for every $\mathrm{x}$ in the base following y.

- f.MaxStress: Return one violation mark if the main stressed syllable of the input does not have a correspondent in the output.

m.1s and m.2s are markedness constraints (hence the prefix m.) guaranteeing the templatic mono- or disyllabic shape of the truncatum. f.AnchL, f.AnchR and f.MaxStress are faithfulness constraints demanding that syllables at the left or right edge, or the stressed syllable of the base, be preserved in the truncatum. f.AnchL and f.AnchR assign penalties for each syllable close to the left or, respectively, right edge not mapped to the output truncatum. This definition accounts for gradiency effects encountered in some truncation patterns where anchoring is leftmost, but to a non-initial syllable whenever the initial syllable is suboptimal as an anchor point e.g. because it is missing an onset (see Alber \& Arndt-Lappe, 2012 and Alber \& Arndt-Lappe, submitted, for discussion).

The evaluation of BTT's candidate set by the set of constraints in BTT.Con yields a factorial typology of 12 truncation patterns, all of which are attested with different degrees of frequency in the world's languages. In Table 1, we focus on 8 of these patterns - those playing a role in our elicitation of the perceived age of truncation patterns in Italian, French and German. The eight patterns in Table 1 take their names from the output they yield for a specific input, the input [abCde], which represents a five-syllable string with antepenultimate stress. This input is maximally distinctive in the sense that it uniquely identifies the patterns under discussion in this paper. Pattern [a] stands for a monosyllabic, left-anchoring pattern, as exemplified by the Italian truncated name Fra, derived from the base name Francésca. Pattern [ab] is again leftanchoring, but disyllabic, and thus represents Italian short names such as Fránce. The truncation Francésca $>$ Césca is ambiguous between an interpretation as pattern [de] (disyllabic, rightanchoring), pattern [Cd] (disyllabic, stress-anchored, stretching to the right) or pattern [Cde] (preserving base material from the stressed to the rightmost syllable). It just so happens that stress is penultimate in Francésca, as in most Italian names, and that therefore the disyllabic portion of the word anchoring to the stressed syllable coincides with the two last syllables of the word and with the portion stretching from the stressed to the rightmost syllable.

The French truncation patterns for which we have elicited the perceived age correspond to the first six patterns in Table 1. Pattern [a] is exemplified by truncations such as Sophie > 
Table 1: Italian, French, German truncation patterns in BTT.

\begin{tabular}{|l|l|l|l|l|l|}
\hline \# & $\begin{array}{l}\text { Truncation } \\
\text { pattern } \\
\text { input: } \\
\text { [abCde] }\end{array}$ & $\begin{array}{l}\text { Size and } \\
\text { anchoring }\end{array}$ & \multicolumn{1}{|c|}{ Italian } & French & German \\
\hline 1 & a & mono, left & Francésca $>$ Fra & $\begin{array}{l}\text { Sophíe }>\text { Soph } \\
\text { Sophíe }>\text { So }\end{array}$ & $\begin{array}{l}\text { Mártin }>\text { Márt-1 } \\
\text { Matthías }>\text { Mátth-i } \\
\text { Katharína }>\text { Kath }\end{array}$ \\
\hline 2 & e & mono, right & & $\begin{array}{l}\text { Isabélle }>\text { Be-bélle } \\
\text { Antóine }>\text { Toine }\end{array}$ & Ánton $>$ Tón-i \\
\hline 3 & C & mono, stress & & $\begin{array}{l}\text { Isabélle }>\text { Be-bélle } \\
\text { Antóine }>\text { Toine }\end{array}$ & $\begin{array}{l}\text { Mártin }>\text { Márt-1 } \\
\text { Sebástian }>\text { Bást-i }\end{array}$ \\
\hline 4 & ab & di, left & Francésca $>$ Fránce & Isabélle $>$ Isá & Sebástian $>$ Séba \\
\hline 5 & de & di, right & Francésca $>$ Césca & Isabélle $>$ Zabélle & Matthías $>$ Hías \\
\hline 6 & bC & di, stress, left & & Isabélle $>$ Zabélle & \\
\hline 7 & Cd & di, stress, right & Francésca $>$ Césca & & Matthías $>$ Hías \\
\hline 8 & Cde & stress-to-final & Francésca $>$ Césca & & Matthías $>$ Hías \\
\hline
\end{tabular}

Soph or Sophie $>$ So. Both short names instantiate a monosyllabic, left-anchored pattern, with the former parsing base material as a coda, the latter realizing an open syllable, instead. Isabélle $>$ Be-bélle and Antóine > Tóine are both ambiguous examples, which can be interpreted as monosyllabic truncation patterns anchoring either to the stressed or to the rightmost syllable, two positions which in French coincide. Be-bélle, in addition to -bélle, the truncatum proper, sports the reduplicative prefix $b e$-, realizing an open syllable template preserving the initial segments of the truncatum. Isabélle > Isá is unambiguously identified as a representative of the disyllabic, left-anchored pattern [ab]. Isabélle $>$ Zabélle, on the other hand, is ambiguous between right-anchored [de] and stress-anchored, left-stretching [bC].

Among the German patterns, we have three which can be interpreted as patterns of the [a] type and are exemplified by Mártin > Márt-l (with the suffix -l), Matthias > Mátth-i (with the suffix - $i$ ) and Katharina $>$ Kath. Of these three, Márt-l could also be interpreted as being of type [C]. This ambiguity could be resolved, if we chose base names with non-initial stress undergoing the same truncation process, but since l-truncations represent, as we will see, a rather old pattern, we only found unambiguous examples such as Bartholomáeus $>$ Bárt-l, which we could not use for our data elicitation because of the low frequency of the base name. The pattern exemplified by Ánton > Tón-i corresponds to monosyllabic, right-anchored [e] and is suffixed with $-i$, as is stress-anchored Sebástian > Bást-i $(=[\mathrm{C}])$. Sebástian $>$ Séba represents the disyllabic, left-anchored pattern [ab]. Matthias $>$ Hias could be interpreted as right-anchored [de], stressanchored $[\mathrm{Cd}]$ or as pattern [Cde], preserving base material from the stressed to the rightmost syllable. We classify the pattern here as disyllabic, since the preserved portion Hias corresponds to a string of segments extending over two syllables in the base name. The truncatum is most probably monosyllabic, via contraction of the two hiatus vowels into a diphthong.

The factorial typology generated for BTT in Alber \& Arndt-Lappe (ibid.) allows us to undertake a first classification of the truncation patterns in the three languages we are investigating. However, we do not know yet how these patterns are generated in the typological system. The grammatical forces determining the single patterns emerge once the typological properties, 
i.e. the ranking conditions defining the typological system, are extracted from the grammars underlying the patterns. Alber \& Arndt-Lappe (submitted) propose five typological properties to be active in BTT.

Table 2: The properties of BTT.

\begin{tabular}{|l|l|l|}
\hline Property & Definition & Extensional trait \\
\hline \hline \multicolumn{2}{|c|}{ Anchoring } \\
\hline Edge.L/R & f.AnchL $<>$ f.AnchR & edge-orientation: left vs. right anchored \\
\hline Prom.stress/edge & f.MaxStress $<>$ EDGE.dom & stress anchoring vs. edge anchoring \\
\hline \hline \multicolumn{2}{|c|}{ Length } \\
\hline Trunc.noT/T & EDGE.sub $<>$ TMPL.dom & no truncation vs. some truncation \\
\hline Length.long/short & PROM.sub $<>$ TMPL.dom & $\begin{array}{l}\text { double vs. single anchoring }= \\
\text { long truncation (e.g. [Cde]) vs. } \\
\text { short (templatic) truncation }\end{array}$ \\
\hline Tmpl.di/mono & m.2s $<>\mathrm{m} .1 \mathrm{~s}$ & \begin{tabular}{l} 
template size: di- vs. monosyllabic \\
\hline
\end{tabular}
\end{tabular}

\begin{tabular}{|l|l|}
\hline \multicolumn{2}{|l|}{ Constraint classes } \\
\hline Constraints in class & Comment \\
\hline TMPL $=\{\mathrm{m} .1 \mathrm{~s}, \mathrm{~m} .2 \mathrm{~s}\}$ & $\begin{array}{l}\text { TMPL is the class of constraints demanding templatic } \\
\text { mono- or disyllabic shape }\end{array}$ \\
\hline EDGE $=\{$ f.AnchL, f.AnchR $\}$ & $\begin{array}{l}\text { EDGE is the class of constraints demanding left and } \\
\text { right anchoring }\end{array}$ \\
\hline PROM = f.MaxStress, EDGE.dom & $\begin{array}{l}\text { PROM is the class of constraints referring to anchor } \\
\text { points (left, right, and stress })\end{array}$ \\
\hline
\end{tabular}

In Table 2, the typological properties of BTT are listed in the first column using the format "Name of property.value $\mathrm{x} /$ value $\mathrm{y}$ ". "Edge.L/R" thus reads: "property Edge, which has two values: $\mathrm{L}$ and $\mathrm{R}$ ". The definition of the property in the second column displays the ranking conditions determining the two values where domination by the constraint (or constraint class) on the left realizes value $\mathrm{x}$ and the reverse ranking realizes value $\mathrm{y}$. The ranking f.AnchL > f.AnchR therefore yields the property value Edge.L and f.AnchR $>$ f.AnchL the property value Edge.R.

The first two properties in Table 2 determine the anchoring properties of the truncation pattern. The value of the property Edge.L/R decides whether a pattern is left-anchored, as pattern [a], or right-anchored, as pattern [e]. This property is defined by the antagonism between the constraints f.AnchL and f.AnchR. If in some grammar the former dominates the latter, we get a left-anchoring pattern, which will be specified for the property value Edge.L. Under the opposite ranking, patterns will be specified for Edge.R.

The second property in Table 2 is about the contrast between stress-anchoring patterns, such as [C], and edge-anchoring patterns, such as [a] or [e]. This property sees as antagonists the constraint f.MaxStress and the class of EDGE constraints, f.AnchL and f.AnchR. A pattern displays stress-anchoring whenever f.MaxStress dominates the dominant (and hence both) of the two EDGE constraints, as expressed by the dom suffix attached to the class identifier $E D G E$. Edge-anchoring, i.e. the property value Prom.edge, emerges under the opposite ranking 
condition, EDGE.dom $>$ f.MaxStress. The meaning of this ranking condition is that to obtain an edge-anchoring pattern, the dominant of the EDGE constraints (hence at least one of them) must dominate f.MaxStress.

The next three properties in Table 2 are concerned with the length of truncation. The ranking condition Trunc.noT/T specifies the circumstances under which a base will or will not be truncated. No truncation takes place if the subordinate EDGE constraint (hence both of them) dominates the class of TMPL constraints $\mathrm{m} .1 \mathrm{~s}$ and $\mathrm{m} .2 \mathrm{~s}$. These constraints strive to obtain a templatic mono- or disyllabic shape for the truncatum, hence are the main triggers for truncation. The EDGE constraints are their antagonists: they would like to include in the truncatum all segments of the base up to its left and right edge. To obtain any truncation at all, the opposite ranking condition, TMPL.dom $>$ EDGE.sub must be operative. This ranking condition, expliciting the property value Trunc.T, states that the dominant (hence at least one of the) TMPL constraints must dominate the subordinate (hence at least one of the) EDGE constraints. The strive towards a templatic shape has to break anchoring to both edges for truncation to take place.

The property Length.long/short decides the contrast between short, templatic truncations, as [a] or [ab], and 'long' truncations, such as [abC] or [Cde]. Long truncation patterns where base material is copied from the initial to the stressed syllable, as in [abC], do occur in natural languages. They are exemplified by a pattern of Central/Southern Italian vocatives where e.g. Antonélla is truncated to Antoné, with the portion of the truncatum preserved stretching from the first to the stressed syllable of the base (see Alber, 2010; Alber \& Arndt-Lappe, submitted; D'Alessandro \& van Oostendorp, 2016; Kenstowicz, 2019; Vanrell \& Cabré, 2011). In our exploration of the perceived age of truncation patterns in Italian, French and German, we encounter long truncation patterns as one possible interpretation of the patterns underlying truncated names such as Francésca $>$ Césca (see discussion above). For long truncation to take place, the subordinate of the class of PROM constraints (hence both of them) have to dominate both TMPL constraints. The class of PROM constraints includes f.MaxStress and EDGE.dom. The requirement of long truncation patterns that both of them dominate the TMPL constraints can be translated into the requirement that both f.MaxStress and one of the EDGE constraints (at least the dominant one) dominate the TMPL constraints. It is understandable that this should be the requirement for long truncation patterns since what characterizes them is double anchoring - to the stressed syllable and one of the two edges.

The fifth and last property proposed by Alber \& Arndt-Lappe (submitted) is the property Tmpl.di/mono, which decides whether the truncated forms display di- or monosyllabic templates, depending on the ranking of the TMPL constraints $\mathrm{m} .2 \mathrm{~s}$ and $\mathrm{m} .1 \mathrm{~s}$ with respect to each other.

The properties of BTT allow us to classify the truncation patterns that we are investigating for Italian, French and German in intensional terms, i.e. with respect to the grammatical forces that generate them. In Table 3, we classify the patterns of Table 1 according to their property values, i.e. according to the ranking conditions they satisfy. ${ }^{3}$

The stage is now set for an exploration of the hypothesis outlined in Section 1 that patterns forming adjacent steps on a diachronic path are distinguished in terms of minimal differences in property values. In order to verify this hypothesis, we first have to establish the relative diachrony between the single patterns in each language.

3 For conciseness we omit the property Trunc.noT/T since all the patterns under discussions do exhibit some truncation and hence have the value Trunc.T. Also, the examples representing pattern [Cde] can not be classified with respect to the property Tmpl.di/mono, since this property emerges only in truncations based on base names with final stress. 
Table 3: Italian, French, German patterns classified according to property values.

\begin{tabular}{|l|l|l|l|l|l|l|}
\hline \# & $\begin{array}{l}\text { Truncation } \\
\text { pattern }\end{array}$ & $\begin{array}{l}\text { Length. } \\
\text { long/short }\end{array}$ & $\begin{array}{l}\text { Tmpl. } \\
\text { di/mono }\end{array}$ & $\begin{array}{l}\text { Prom. } \\
\text { stress/edge }\end{array}$ & $\begin{array}{l}\text { Edge. } \\
\text { L/R }\end{array}$ & Examples \\
\hline a & short & mono & edge & L & $\begin{array}{l}\text { It: Francésca }>\text { Fra } \\
\text { Fr: Sophíe }>\text { Soph } \\
\text { G: Katharína }>\text { Kath }\end{array}$ \\
\hline 3 & e & short & mono & edge & R & $\begin{array}{l}\text { Fr: Antóine }>\text { Toine } \\
\text { G: Ánton }>\text { Tón-i }\end{array}$ \\
\hline 4 & ab & short & mono & stress & & $\begin{array}{l}\text { Fr: Antóine }>\text { Toine } \\
\text { G: Sebástian }>\text { Bást-i }\end{array}$ \\
\hline 5 & de & short & di & edge & L & $\begin{array}{l}\text { It: Francésca }>\text { Fránce } \\
\text { Fr: Isabélle }>\text { Isá } \\
\text { G: Sebástian }>\text { Séba }\end{array}$ \\
\hline 6 & bC & short & di & edge & R & $\begin{array}{l}\text { It: Francésca }>\text { Césca } \\
\text { Fr: Isabélle }>\text { Zabélle } \\
\text { G: Matthías }>\text { Hías }\end{array}$ \\
\hline 7 & Cd & short & di & stress & R & $\begin{array}{l}\text { It: Francésca }>\text { Césca } \\
\text { G: Matthías }>\text { Hías }\end{array}$ \\
\hline 8 & Cde & long & mono/di & & R & $\begin{array}{l}\text { It: Francésca }>\text { Césca } \\
\text { G: Matthías }>\text { Hías }\end{array}$ \\
\hline
\end{tabular}

\section{Language change in truncation: Italian, French and German}

In this section, we describe data collection and results for the perceived age of name truncation patterns in Italian, French and German. To our knowledge, the first study in this domain was undertaken for Italian patterns in a 2017 term paper by Laura Boschiroli, supervised by Birgit Alber at the University of Verona. We build on Boschiroli's methods and findings, extending the empirical domain to French and German truncation patterns, for which we collected data in 2020. Boschiroli's and our data elicitation have still to be considered pilot studies, considering the types and amount of data elicited. The first results which they yield are nevertheless promising: it seems that relative perceived age indeed emerges as a category distinguishing the various truncation patterns of a language.

\subsection{Methods of data elicitation}

To control for areal variation, we elicited data for French and German in a circumscribed geographical region, namely Belgium and South Tyrol (see Table 4). The same holds for Boschiroli, who elicited her data exclusively in the Northern Italian region of Veneto.

Boschiroli interviewed her informants directly, whereas we created an online questionnaire and shared its URL (https://sites.google.com/view/bzcrowdsourcing/) via e-mail or Facebook to reach participants from our outer social network (e.g. friends of friends).

Boschiroli elicited data for 4 Italian truncation patterns corresponding to those listed in Table 1, plus the i-final pattern exemplified by Francésca $>$ Fránc-i. We ignore this last pattern in our analysis, since it is not clear whether it should be interpreted as a left-anchored 
monosyllabic pattern suffixed with $-i$ (hence a pattern of the [a] type), or whether the final $i$ is a default vowel overwriting the final vowel of a left-anchored disyllabic [ab] pattern. An argument for the latter interpretation would be the fact that Italian i-truncations, differently from German i-truncations, realize more than the templatic heavy-syllable truncatum usually encountered in [a] patterns. This becomes clear when comparing the truncation of Italian Andréa $>$ Ándri to German Andréas > Ánd-i. We do not want to burden our analysis with this indeterminacy, hence omit the i-pattern from further consideration.

The perceived age of each pattern was elicited by Boschiroli for a total of 35 basetruncatum test items. Her choice of base names depended on whether minimal pairs of truncated forms were attested for it, as is e.g. the case for the base name Francésca which can be truncated to Fra, Fránce or Césca. This had the disadvantage that it lead to an imbalanced set of test items with respect to the representation of patterns: 13 items for the pattern Césca (ambiguous between patterns [Cde], [de] and [Cde]), 11 items for [ab] patterns of the Fránce type, but only 4 items for [a] patterns like Fra. We analyze her data according to the same criteria as our own, keeping however in mind that a comprehensive elicitation of the perceived age of Italian truncation patterns has still to be undertaken.

For our data elicitation of French and German truncation patterns, we prepared a set of test items representing 6 truncation patterns of French and 7 patterns of German. Examples of these patterns are listed in Table 1. For each of the truncation patterns, we chose at least two examples of attested base names and their truncated forms, arriving at a total of 16 items for French and 23 for German. The base names were chosen among the 100 most frequent names in Belgium, according to the STATBEL service 2017-19 (STATBEL, 2020) and the 100 most frequent in South Tyrol, according to the ASTAT survey from 2017 (ASTAT, 2018). For French, we chose only base names borne by people in the age group 18-64; for German, we selected base names where the average age of people bearing them was below 60 . Controlling for frequency of the base name should guarantee that no base names which are either too old or too new are among the test items, which might influence participants to respond to the perceived age of the base name rather than to that of the truncated name. The average age of people bearing the base name is important as well: Josef, for instance, is the most frequent male first name in South Tyrol, but its frequency is due to its past fortune as a popular name, given that the average age of people called Josef was 64 in 2017.

Boschiroli (2017) asked her participants whether 1) they know the short name $X$ for somebody called $Y$; and 2) how old they think a person called $X$ might be. In our research on French and German, we asked instead whether the participant could imagine that the short name $X$ for $Y$ exists, and if yes, how old a person with that name would be (the perceived age). In all questionnaires, the perceived age of $X$ was asked as an age range (from ... to ... years old), although some participants answered with a specific number instead. Table 4 reports relevant data about participants and their response behavior.

\subsection{Results}

In all three languages, participant age correlated weakly with perceived age $(r=0.108, p<0.001)$ and with the acceptability of the truncated pattern $(r=-0.169, p<0.001)$. This means that 1$)$ participants were likely to answer with ages more similar to their own age, and 2) older participants were more likely to reject name truncations as unknown/unacceptable. This inverse correlation between the age of the participants and their willingness to accept a given truncated name (correlation 2) is reflected in Table 4 simultaneously as a higher participant age for French $>$ Italian $>$ German and as a higher acceptability for German $>$ Italian $>$ French. On the other 
Table 4: Participant metadata and response data.

\begin{tabular}{|c|c|c|c|c|}
\hline \multirow{2}{*}{ Lang. } & \multicolumn{4}{|c|}{ Metadata } \\
\hline & $\begin{array}{l}\text { Number of } \\
\text { participants }\end{array}$ & Place of origin & Place of residence & $\begin{array}{l}\text { Participant } \\
\text { age }\end{array}$ \\
\hline Italian & 13 & $\begin{array}{l}<53 \mathrm{~km} \text { from Padova, } \\
<52 \mathrm{~km} \text { from Vicenza }\end{array}$ & (no data) & $\begin{array}{r}\text { Mean: } 45.2 \\
\text { SD: } 20.1\end{array}$ \\
\hline French & 56 & $\begin{array}{l}<110 \mathrm{~km} \text { from Brussels } \\
(1 \text { exception: } 807 \mathrm{~km})\end{array}$ & $<60 \mathrm{~km}$ from Brussels & $\begin{array}{r}\text { Mean: } 53.6 \\
\text { SD: } 23.5 \\
\end{array}$ \\
\hline German & 25 & $<72 \mathrm{~km}$ from Bozen & $\begin{array}{c}<72 \mathrm{~km} \text { from Bozen } \\
\text { (1 exception: } 947 \mathrm{~km})\end{array}$ & $\begin{array}{r}\text { Mean: } 31.9 \\
\text { SD: } 15.6\end{array}$ \\
\hline \multirow{2}{*}{ Lang. } & \multicolumn{4}{|c|}{ Response data } \\
\hline & $\begin{array}{c}\text { Average } \\
\text { perceived age }\end{array}$ & $\begin{array}{l}\text { Average difference between } \\
\text { min and max perceived age }\end{array}$ & $\begin{array}{c}\text { Acceptability } \\
\text { (known/imaginable) }\end{array}$ & $\begin{array}{c}\text { Number of } \\
\text { items (names) }\end{array}$ \\
\hline Italian & $\begin{array}{r}\text { Mean: } 45.6 \\
\text { SD: } 24.3\end{array}$ & $\begin{array}{r}\text { Mean: } 31.1 \\
\text { SD: } 21.9\end{array}$ & Mean: $67.6 \%$ & $28(17)$ \\
\hline French & $\begin{array}{r}\text { Mean: } 37.1 \\
\text { SD: } 17.5\end{array}$ & $\begin{array}{r}\text { Mean: } 39.5 \\
\text { SD: } 26.1\end{array}$ & Mean: $50.9 \%$ & $16(9)$ \\
\hline German & $\begin{array}{r}\text { Mean: } 40.4 \\
\text { SD: } 19.9\end{array}$ & $\begin{array}{r}\text { Mean: } 51.6 \\
\text { SD: } 29.2\end{array}$ & Mean: $77.9 \%$ & $23(14)$ \\
\hline
\end{tabular}

hand, the correlation between participant age and perceived age (correlation 1) is not reflected in the French data in Table 4, where the perceived age is low on average. This is a likely consequence of the fact that despite having carefully selected first names for their average age in the population, differences in the perceived age of base names and truncated names subsist (for example, in the ranking according to average perceived age, the nine oldest names are Italian or German, followed by French Robert, followed again by four Italian or German names).

In all three languages, an ANOVA indeed shows that the perceived age is significantly influenced by the base name, the truncated name, the truncation pattern and the truncation anchoring ( $p<0.001$ for each variable, within each language). ${ }^{4}$ This confirms that notwithstanding our controlling for the frequency and average age of people bearing a base name, some influence of the base name on the perceived age of the truncated form persists. Given this finding, it might be useful to consider designing further experiments in this domain with the help of nonce base names, which would neutralize this language-external influence on the perceived age of truncated forms.

\subsubsection{Italian}

For each Italian name, the left-anchored variant was perceived as younger (statistically significant in 7 out of 9 relevant cases). The left-anchored monosyllabic pattern was significantly younger than the left-anchored disyllabic pattern in the only relevant case $(t=-2.293, p=0.048)$. Figure 1 illustrates the perceived age per truncation pattern (where an underscore separates possible interpretations of an ambiguous pattern).

The difference between [Cd_de_Cde] vs. [a] and [ab] is highly significant $(t=-12.238$, $p<0.001$ ), but not that between [a] and [ab]. Boschiroli posits (mostly based on data-external

$4 \quad$ Hereafter, all significant results were tested both with and without participant as a random variable. 


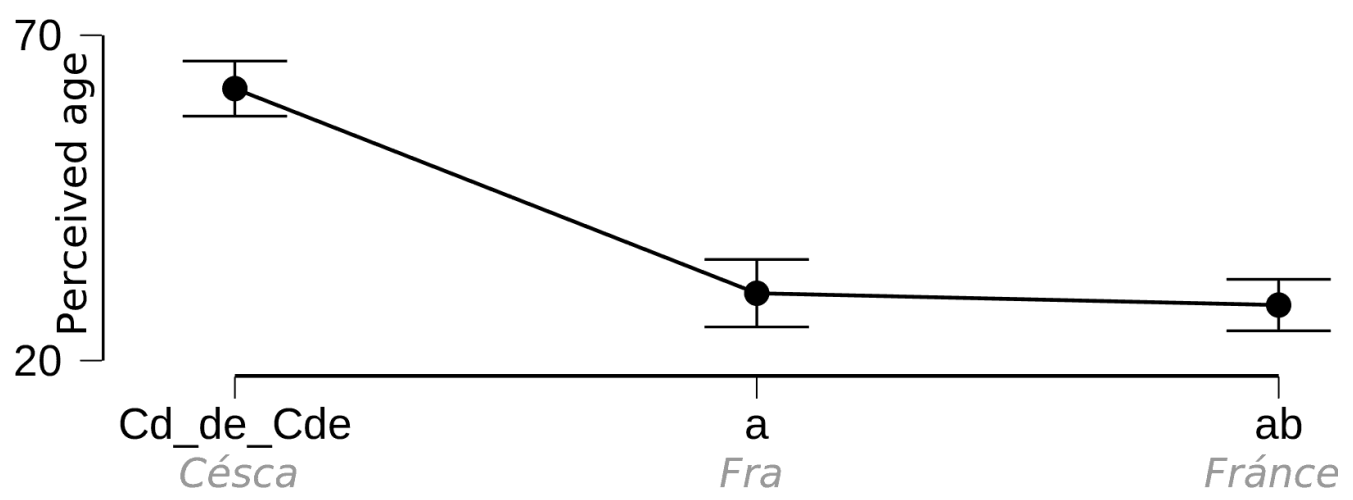

Figure 1: Average perceived age per truncation pattern in Italian.

experience) that the left-anchored monosyllabic [a] pattern is younger than the left-anchored disyllabic [ab] pattern, an observation which we share, but for which additional data would be required to be able to support this claim statistically. The data thus allows to establish the relative chronology $\{\mathrm{Cd}$ _de_Cde $\}>\{\mathrm{a}(\mathrm{b})\}$ with statistical support, but is too scarce to allow for any further distinction within the second set.

\subsubsection{French}

With 4.3 times more participants, the French data reveal a similar pattern, yet with stronger statistical support. The two patterns perceived as oldest, [C_e-Red] and [C_e] (Isabélle $>$ Be-bélle, Antóine $>$ Toine), do not differ significantly in perceived age and neither do the three following patterns among themselves ([bC_de], [ab], [a-Coda]). Pattern [a] is significantly perceived as younger than $[\mathrm{ab}]$ and [a-Coda] $(t=2.785 \& 2.619, p=0.006 \& 0.009)$. The perceived age per truncation pattern in French is shown in Fig. 2.

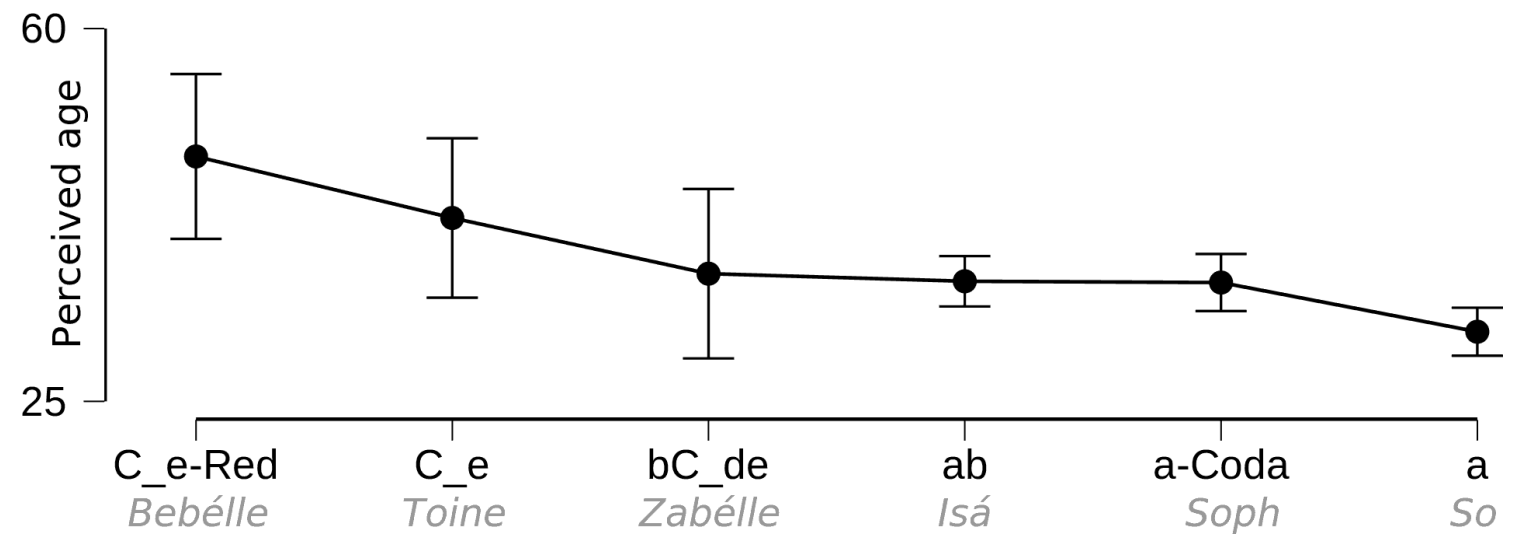

Figure 2: Average perceived age per truncation pattern in French.

By grouping together the non-significantly distinguished patterns, ${ }^{5}$ one obtains the relative chronology $\left\{\mathrm{C}_{-} \mathrm{e}(-\mathrm{Red})\right\}>\left\{\mathrm{bC} \_\mathrm{de}, \mathrm{ab}, \mathrm{a}-\mathrm{Coda}\right\}>\{\mathrm{a}\}$, where the average perceived age of each set differs from the neighboring sets with a $t$-value not closer to zero than 2.9186 and a $p$-value not superior to 0.004 . This chronology is very similar to the Italian chronology, except

$5 \quad$ The method used here to obtain a chronology consists of: 1) running a $t$-test for all possible pairs of truncation patterns, 2) merging together the two truncation patterns whose $p$-value is highest (i.e. least significant) if and only if their $p>0.05,3$ ) repeating the procedure until all $t$-test comparisons are significant. 
that the hypothesis of a younger age for the left-anchored monosyllabic pattern is supported by statistical evidence in this case.

\subsubsection{German}

Tyrolean German differs from the other two languages by having a left-anchored, monosyllabic pattern with the diminutive suffix $-l$ besides patterns with the frequently encountered suffix $-i$. As Fig. 3 shows, patterns suffixed with the $l$-suffix are perceived as even older than rightanchored and stress-anchored truncation patterns.

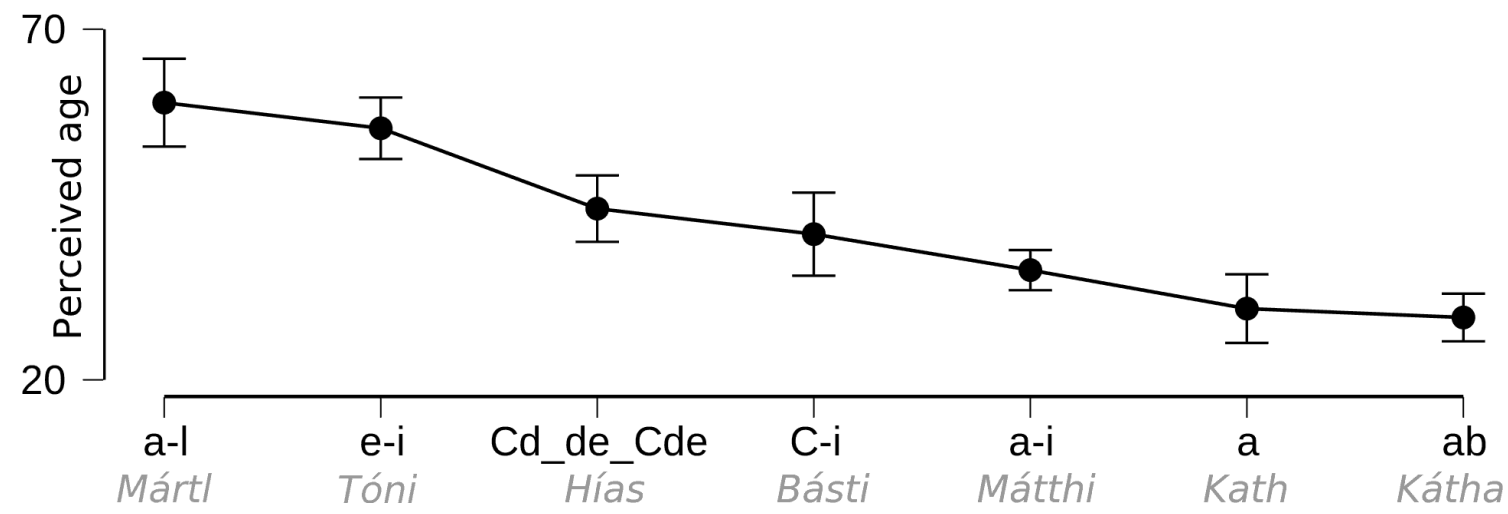

Figure 3: Average perceived age per truncation pattern in German.

The chronology resulting from the data is $\{\mathrm{a}-1, \mathrm{e}-\mathrm{i}\}>\{\mathrm{Cd}$ de_Cde, $\mathrm{C}-\mathrm{i}\}>\{\mathrm{a}-\mathrm{i}\}>\{\mathrm{a}, \mathrm{ab}\}$, where the average perceived age of each set differs from the neighboring sets with at least $t=2.931$ and at most $p=0.004$.

\section{Paths of minimal change}

In this section, we return to our initial hypothesis that language change in truncation involves minimal grammatical change in terms of typological properties. The hypothesis states that any two patterns which differ minimally in perceived age should also differ minimally in the set of property values that define them. Before checking whether the difference between chronologically adjacent patterns is indeed minimal in this sense, we first want to clarify how we treat ambiguous patterns and how patterns whose chronological relationship cannot be established on statistical grounds are dealt with.

For some of the patterns that we have been investigating, a classification in terms of property values is necessarily ambiguous. As discussed in section 2, the Italian truncation pattern Francésca > Césca could be classified as stress-anchored disyllabic [Cd], as right-anchored disyllabic [de], or even as a pattern preserving base material from the stressed to the final syllable [Cde]. With respect to our hypothesis of minimal grammatical change, we will assume that it is fulfilled if at least one of the possible classifications of a pattern exemplified by basetruncatum pairs such as Francésca $>$ Césca can be linked via minimal steps to the preceding and the following step in the diachronic path. In the discussion that follows, we will therefore only list those classifications of ambiguous patterns which indeed contribute to the creation of a diachronic path with minimal links.

The second issue which has to be tackled is how to deal with groups of patterns whose relative diachronic relationship could not be determined on statistical grounds. For instance, the difference in perceived age between the German pattern [a] (Katharina > Kath), and [ab] 
(Sebástian $>$ Séba) is not statistically significant in our study. This could be due to a number of factors such as the choice of the base name, the size of our sample, the age of participants, or even to the fact that Katharina $>$ Kath and Sebástian $>$ Séba are both new truncation patterns in German, which might not (yet) be perceived as distinguishable in terms of perceived age. It could also be due to the fact that some of the patterns involved are distinguished by their pragmatic function (e.g. the expression of various degrees of closeness) rather than age. While we must leave the exploration of these factors to further research, we will check whether our hypothesis of a diachronic path consisting of minimal grammatical steps is consistent with, even if not fully determined by, the statistical findings on the chronology of patterns. Thus, we will check whether some order of the patterns Katharina $>$ Kath and Sebástian $>$ Séba with respect to each other is consistent with the idea that diachronic steps correspond to minimal steps in property values. The advantage of such a procedure is that once we have established a possible diachronic path characterized by grammatical minimality, we can go back to the patterns and, with the help of further data elicitation, work on concrete hypotheses of which patterns should be perceived as older or more recent. We therefore consider ourselves at the very beginning of a promising process of theoretically informed empirical investigation in a productive to-and-from between theoretical analysis and data elicitation, bringing us ever closer to the truth concerning the intralinguistic variability of truncation patterns.

In what follows, we will outline the minimal diachronic paths that we found for Italian, French and German truncation patterns. The tables illustrate via shading which property distinguishes one pattern from the next. Vertical double lines separate patterns or groups of patterns whose significantly distinct relative diachrony could be established on statistical grounds, whereas single lines divide patterns where this is not the case. Dotted lines distinguish two interpretations of the same pattern, which however are both crucial for the generation of the diachronic path. As mentioned above, we omitted all alternative classifications which could not be accommodated in it. Suffixes as well as reduplicative prefixes in the patterns are ignoredthe patterns are stripped down to their basic classification in terms of size and anchoring.

Table 5: Diachronic path with minimal links - Italian patterns.

\begin{tabular}{|l|c||c|c|}
\hline & de & ab & a \\
\cline { 2 - 4 } & Francésca $>$ Césca & Francésca $>$ Fránce & Francésca $>$ Fra \\
\hline Length & short & short & short \\
\hline Tmpl & di & di & mono \\
\hline Prom & edge & edge & edge \\
\hline Edge & R & L & L \\
\hline
\end{tabular}

As Table 5 shows, Italian truncation patterns can be inserted into a diachronic path whose links are minimal in a grammatical sense. Thus, one interpretation of the pattern Francésca $>$ Césca, namely [de], shares all property values with the next diachronic step, [ab], except the value referring to the property Edge. The grammars of the two patterns in fact are distinguished by the ranking of the constraints f.AnchL and f.AnchR, which determine whether a pattern is anchored to the left or the right edge of the word. Similarly, there is a minimal difference between patterns [ab] (Francésca $>$ Fránce) and [a] (Francésca $>$ Fra) with respect to the property Tmpl. The former pattern is disyllabic $(\mathrm{m} .2 \mathrm{~s}>\mathrm{m} .1 \mathrm{~s})$, the latter monosyllabic $(\mathrm{m} .1 \mathrm{~s}>\mathrm{m} .2 \mathrm{~s})$. The relative perceived age of these patterns could not be determined on statistical grounds, as indicated by the single lines dividing them. However, the diachronic order [ab] $>[a]$ is consistent with the hypothesis of minimal change (while the opposite order is not). Interestingly, this is also the 
chronology that corresponds to Boschiroli's and our intuition of change in Northern varieties of Italian.

Table 6: Diachronic path with minimal links - French patterns.

\begin{tabular}{|l|c||c|c||c|}
\hline \multirow{2}{*}{ a. } & $\mathbf{C}$ & $\mathbf{b C}$ & $\mathbf{a b}$ & $\mathbf{a}$ \\
\cline { 2 - 5 } & $\begin{array}{l}\text { Isabélle }>\text { Be-bélle } \\
\text { Antóine }>\text { Toine }\end{array}$ & Isabélle $>$ Zabélle & Isabélle > Isá & $\begin{array}{l}\text { Sophie }>\text { Soph } \\
\text { Sophie }>\text { So }\end{array}$ \\
\hline Length & short & short & short & short \\
\hline Tmpl & mono & di & di & mono \\
\hline Prom & stress & stress & edge & edge \\
\hline Edge & & $\mathrm{L}$ & $\mathrm{L}$ & $\mathrm{L}$ \\
\hline
\end{tabular}

\begin{tabular}{|l|c||c|c||c|}
\hline \multirow{2}{*}{ b. } & $\mathbf{e}$ & $\mathbf{d e}$ & $\mathbf{a b}$ & $\mathbf{a}$ \\
\cline { 2 - 5 } & $\begin{array}{l}\text { Isabélle }>\text { Be-bélle } \\
\text { Antóine }>\text { Toine }\end{array}$ & Isabélle $>$ Zabélle & Isabélle > Isá & $\begin{array}{l}\text { Sophie }>\text { Soph } \\
\text { Sophie }>\text { So }\end{array}$ \\
\hline Length & short & short & short & short \\
\hline Tmpl & mono & di & di & mono \\
\hline Prom & edge & edge & edge & edge \\
\hline Edge & $\mathrm{R}$ & $\mathrm{R}$ & $\mathrm{L}$ & $\mathrm{L}$ \\
\hline
\end{tabular}

For French, two possible diachronic paths can be established, depending on the classification we choose for ambiguous patterns. In Table 6a., patterns exemplified by Isabélle $>$ Be-bélle, Antóine $>$ Tóine and Isabélle $>$ Zabélle are interpreted as stress-anchored ([C] or [bC]). In 6b., they are interpreted as anchored to the right edge ([e] or [de]). Our hypothesis for change in minimal steps holds in both cases. For reasons of space, we will discuss it in detail only for the first.

In the diachronic path established for French truncation patterns, a single change in the value of the property Tmpl - from monosyllabic to disyllabic - links the oldest patterns of the $[\mathrm{C}]$ type to more recent patterns of type $[\mathrm{bC}]$. A change in value of the property Prom then links stress-anchored $[\mathrm{bC}]$ to edge-anchored $[\mathrm{ab}]$. This means that the grammars of the two patterns are distinguished by the single ranking condition defined by the property Prom: in the grammar of $[\mathrm{bC}]$ f.MaxStress dominates both EDGE constraints (f.AnchL and f.AnchR), while in $[a b]$ the logically opposite value holds, i.e. one of the EDGE constraints, in this case f.AnchL, dominates f.MaxStress. Both grammars are otherwise identical. The next step in the chronology sees pattern [ab] linked to [a] via a minimal change in the property Tmpl, as was the case in the first step between $[\mathrm{C}]$ and $[\mathrm{bC}]$. While the relative chronology of $[\mathrm{bC}]$ and $[\mathrm{ab}]$ is not determined by statistical findings, as the single line dividing them suggests, the hypothesized order $[\mathrm{bC}]>$ $[a b]$ is consistent with them. Overall, the French patterns display an interesting chronology from monosyllabic to disyllabic, then back to monosyllabic patterns, with a change, persisting in time, from stress-anchored (or right-anchored) to left-anchored patterns.

The diachronic path connecting in a minimal fashion different truncation patterns of German is particularly long and winding (see Table 7). The oldest patterns [a] and [e] are distinguished, apart from the suffixes $-l$ and $-i$, also by a minimal change in the value of the property Edge, which determines to which edge the pattern is anchored. Pattern [e] leads to [de], the pattern 
Table 7: Diachronic path with minimal links - German patterns.

\begin{tabular}{|l|c|c||c|c|c||c||c|c|}
\hline & $\mathbf{a}$ & $\mathbf{e}$ & $\mathbf{d e}$ & $\mathbf{C d}$ & $\mathbf{C}$ & $\mathbf{a}$ & $\mathbf{a b}$ & $\mathbf{a}$ \\
\cline { 2 - 6 } & $\begin{array}{l}\text { Mártin } \\
>\text { Márt-l} l\end{array}$ & $\begin{array}{l}\text { Ánton } \\
>\text { Tón- } i\end{array}$ & $\begin{array}{c}\text { Matthías } \\
>\text { Hías }\end{array}$ & $\begin{array}{l}\text { Sebástian } \\
>\text { Bást }-i\end{array}$ & $\begin{array}{l}\text { Matthías } \\
>\text { Mátth }-i\end{array}$ & $\begin{array}{l}\text { Sebástian } \\
>\text { Séba }\end{array}$ & $\begin{array}{l}\text { Katharína } \\
>\text { Kath }\end{array}$ \\
\hline Length & short & short & short & short & short & short & short & short \\
\hline Tmpl & mono & mono & di & di & mono & mono & di & mono \\
\hline Prom & edge & edge & edge & stress & stress & edge & edge & edge \\
\hline Edge & L & $\mathrm{R}$ & $\mathrm{R}$ & $\mathrm{R}$ & & $\mathrm{L}$ & $\mathrm{L}$ & $\mathrm{L}$ \\
\hline
\end{tabular}

exemplified by Matthías > Hias, via a minimal change of value in the Tmpl property, from monosyllabic, to disyllabic. In order to connect [de] in a minimal fashion to [C], which is the following pattern exemplified by Sebástian > Básti, we have to assume, however, that another possible classification of Matthías > Hias, namely [Cd], plays a role as well. Assuming that Matthias > Hias is first interpreted as [de] (Prom.edge), but then as [Cd] (Prom.stress), we reach $[\mathrm{C}]$ via change of the property value of Tmpl, rendering the $[\mathrm{Cd}]$ pattern monosyllabic. The next step in the chronology, $[\mathrm{C}]>[\mathrm{a}]$, sees again a change from stress- to edge-anchoring, corresponding to a change of the ranking conditions underlying the property Prom. The [a] pattern exemplified by $i$-suffixed Matthías $>$ Matth-i develops into unsuffixed disyllabic [ab] and, then, monosyllabic [a], exemplified by Sebástian > Séba and Katharína $>$ Kath, respectively. It is interesting to observe that the diachronic path has come full circle: starting with a leftanchored [a] pattern, passing through stages of right- and stress-anchored patterns, we return yet once more to left-anchored patterns of the [a] or [ab] type.

Considering that the probability of two patterns in the full truncation typology (BTT) being minimally different in terms of property values is $\frac{34}{66}$, the a priori likelihood of finding a perfectly minimal path of change with 7 transitions between patterns as in our German example would be $\frac{34}{66}=0.009628195$. This emphasizes that the minimal path which we found is unlikely to be due to mere chance.

\section{Conclusions}

Our elicitation task for French and German as well as the findings of Boschiroli (2017) show that intralinguistic variation of truncation patterns can in many cases be correlated to perceived age. At least part of the multitude of truncation patterns observed in single languages could therefore be considered cases of diachronic change. This type of language change is particularly interesting since it involves a relatively fast change of prosodic structures, which otherwise are known to be rather resistant to change. Our second finding is that the diachronic path connecting the various patterns is compatible with a model of language change in which chronologically adjacent stages are characterized by minimal grammatical variation. Minimal grammatical variation, furthermore, is best understood as minimal variation in the values of a specific type of ranking conditions - typological properties - active in the typology of truncation.

\section{References}

Alber, Birgit. 2010. An exploration of truncation in Italian. In Peter Staroverov et al. (eds.) Rutgers Working Papers in Linguistics. New Brunswick, NJ: LGSA, 1-30. 
Alber, Birgit. 2017. The Book of BTT. Memoirs of the Society of Typological Analysis. ROA1327. url: http://roa.rutgers.edu/article/view/1703.

Alber, Birgit. 2020. Word Stress in Germanic. In Michael T. Putnam \& B. Richard Page (eds.) The Cambridge Handbook of Germanic Linguistics. Cambridge / New York: CUP, 7396.

https://doi.org/10.1017/9781108378291.005

Alber, Birgit \& Sabine Arndt-Lappe. 2012. Templatic and subtractive truncation. In Jochen Trommer (ed.) The Morphology and Phonology of Exponence - the State of the Art. Oxford: OUP, 289-325.

Alber, Birgit \& Sabine Arndt-Lappe. Submitted. Anchoring in Truncation: a typological analysis.

Alber, Birgit \& Alan Prince. 2015. Outline of Property Theory [Entwurf einer verallgemeinerten Eigenschaftstheorie]. Ms., University of Verona / Rutgers University.

Alber, Birgit \& Alan Prince. 2017. The Book of nGX. Memoirs of the Society of Typological Analysis. ROA-1312. url: http://roa.rutgers.edu/article/view/1663.

Alber, Birgit \& Alan Prince. in prep. The Structure of OT Typologies. Ms., Free University of Bozen-Bolzano / Rutgers University.

ASTAT $=$ Autonome Provinz Bozen-Südtirol, Landesinstitut für Statistik / Istituto provinciale di statistica. 2018. Vornamen in Südtirol / Nomi propri in provincia di Bolzano. BozenBolzano. url: https://astat.provinz.bz.it/.

Boschiroli, Laura. 2017. Bestimmung des Alters italienischer Trunkierungsmuster. Term paper, University of Verona.

D'Alessandro, Roberta \& Marc van Oostendorp. 2016. When imperfections are perfect: Prosody, phi-features and deixis in Central and Southern Italian vocatives. In Ernestina Carrilho et al. (eds.) Selected papers from 'Going Romance' 28, Lisbon. Amsterdam: John Benjamins, 61-82.

https://doi.org/10.1075/rllt.10.04dal

Dresher, B. Elan. 2013. The influence of loanwords on Norwegian and English stress. Nordlyd 40.1: 55-65.

https://doi.org/10.7557/12.2475

González, Carolina. 2017. Tipología de los sistemas métricos de veinticinco lenguas pano. In Pilar Valenzuela \& Antoine Guillaume (eds.) Estudios sincrónicos y diacrónicos sobre lenguas Pano y Takana. Amerindia. Vol. 39. 1, 129-172.

Jacobs, Haike. 2003. Why preantepenultimate stress in Latin requires an OT-account. In Paula Fikkert \& Haike Jacobs (eds.) Development in Prosodic Systems. Berlin / New York: De Gruyter, 395-418.

https://doi.org/10.1515/9783110894530.395 
Kenstowicz, Michael. 2019. The analysis of truncated vocatives in Taviano (Salentino) Italian. Catalan Journal of Linguistics 18. https://doi.org/10.5565/rev/catj1.257

Kroch, Anthony S. 2001. Syntactic Change. In Mark Baltin \& Chris Collins (eds.) The Handbook of Contemporary Syntactic Theory. Oxford: Blackwell Publishers Ltd, 699-729. https://doi.org/10.1002/9780470756416.ch22

Lahiri, Aditi. 2015. Change in Word Prosody: Stress and Quantity. In Patrick Honeybone \& Joseph Salmons (eds.) The Oxford Handbook of Historical Phonology. Oxford: OUP. https://doi.org/10.1093/oxfordhb/9780199232819.013.020

Prince Alan, Nazarré Merchant \& Bruce Tesar. 2007-2022. OTWorkplace [software]. url: https: //sites.google.com/site/otworkplace/.

Speyer, Augustin. 2009. On the Change of Word Stress in the History of German. Beiträge zur Geschichte der deutschen Sprache und Literatur (PBB) 131.3: 413-441. https://doi.org/10.1515/bgsl.2009.051

STATBEL $=$ Office belge de statistique. 2020. Noms et prénoms. Brussels. url: https://statbel. fgov.be.

Vanrell, Maria del Mar \& Teresa Cabré. 2011. Troncamento e intonazione dei vocativi in Italia centromeridionale. In Barbara Gili Fivela et al. (eds.) Contesto comunicativo e variabilità nella produzione e percezione della lingua: Atti del $7^{\circ}$ convegno AISV. Rome: Bulzoni.

Zonneveld, Wim. 1999. Word stress in West-Germanic and North-Germanic languages: Introduction. In Harry van der Hulst (ed.) Word Prosodic Systems in the Languages of Europe. Vol. 20. Berlin / New York: De Gruyter, 477-604.

https://doi.org/10.1515/9783110197082.2.477 